\title{
Simultaneous all-optical add and drop multiplexing of 40-Gbit/s OTDM signals using monolithically integrated Mach-Zehnder interferometer
}

Jepsen, Kim Stokholm; Mikkelsen, Benny; Vaa, Michael; Poulsen, Henrik Nørskov; Clausen, Anders; Stubkjær, Kristian; Hess, R.; Duelk, M; Vogt, W; Gamper, E.

Total number of authors:

14

Published in:

Technical Digest Optical Fiber Communication Conference and Exhibit

Link to article, DOI:

10.1109/OFC.1998.657430

Publication date:

1998

Document Version

Publisher's PDF, also known as Version of record

Link back to DTU Orbit

Citation $(A P A)$ :

Jepsen, K. S., Mikkelsen, B., Vaa, M., Poulsen, H. N., Clausen, A., Stubkjær, K., Hess, R., Duelk, M., Vogt, W., Gamper, E., Gini, E., Besse, P. A., Melchior, H., \& Bouchoule, S. (1998). Simultaneous all-optical add and drop multiplexing of $40-$ Gbit/s OTDM signals using monolithically integrated Mach-Zehnder interferometer. In Technical Digest Optical Fiber Communication Conference and Exhibit IEEE.

https://doi.org/10.1109/OFC.1998.657430

\section{General rights}

Copyright and moral rights for the publications made accessible in the public portal are retained by the authors and/or other copyright owners and it is a condition of accessing publications that users recognise and abide by the legal requirements associated with these rights.

- Users may download and print one copy of any publication from the public portal for the purpose of private study or research.

- You may not further distribute the material or use it for any profit-making activity or commercial gain

- You may freely distribute the URL identifying the publication in the public portal 
(a)

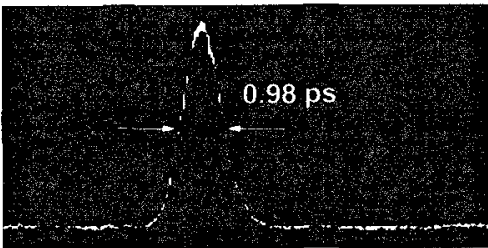

Initial Pulse

(b)

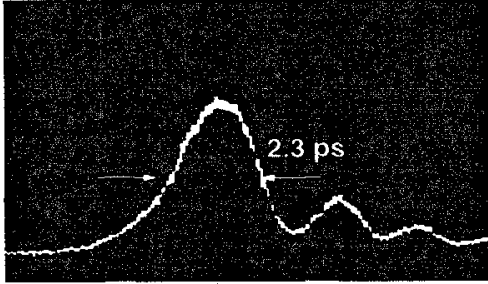

(c)

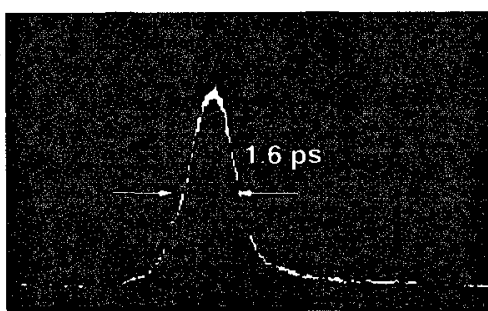

Output Pulse

After $\mathbf{4 0} \mathbf{~ k m}$ Transmission

ThN1 Fig. 3. Measured optical pulse waveforms: (a) Initial pulse; (b) After $40-\mathrm{km}$ transmission with dispersion slope of $0.06 \mathrm{ps} / \mathrm{nm}^{2} / \mathrm{km}$; (c) After $40-\mathrm{km}$ transmission with dispersion slope of $0.02 \mathrm{ps} / \mathrm{nm}^{2} / \mathrm{km}$.

sible by improving the relative timing jitter by optimizing the performance of the PLL.

Finally, PMD of fiber also broadens the pulse width. The average value of PMD of the commercially available dispersion-shifted fiber is 0.1 $\mathrm{ps} / \mathrm{km}^{0.5}$. The influence of the PMD becomes dominant when the transmission length exceeds $100 \mathrm{~km}$ and the reduction of the PMD will be necessary.

In conclusion, Tbit/s TDM transmission will become feasible by combining ultrafast optical signal processing technology, dispersion slope compensation technology, and fiber fabrication technology.

1. S. Kawanishi, H. Takara, T. Morioka, O. Kamatani, K. Takiguchi, T. Kitoh, M. Saruwatari, Electron. Lett. 32, 916-918 (1996).

2. T. Morioka, S. Kawanishi, K. Mori, M. Saruwatari, Electron. Lett. 30, 1166-1168 (1994).

3. A.M. Vengssarkar, A.E. Miller, W.A. Reed, in Optical Fiber Communication Conference \& International Conference on Integrated Optics and Optical Fiber Communication, Vol. 4 of 1993 OSA Technical Digest Series (Optical Society of America, Washington, D.C., 1993), pp. 56-59.

4. O. Kamatani and S. Kawanishi, IEEE J. Lightwave Technol. 14, 1757-1767 (1996).

5. P.A. Andrekson, N.A. Olsson, J.R. Simpson, T. Tanbun-Ek, R.A. Logan, M. Haner, Electron. Lett. 27, 922-924 (1991).

6. T. Morioka, S. Okamoto, M. Ishii, M. Saruwatari, Electron. Lett. 32, 836-837 (1996).

7. H. Takara, S. Kawanishi, T. Morioka, K. Mori, M. Saruwatari, Electron. Lett. 30, 1152-1153 (1994).

8. K. Takiguchi, S. Kawanishi, H. Takara, O. Kamatani, K. Uchiyama, A. Himeno, K. Jinguji, Electron. Lett. 32, 2083-2085 (1996).
Simultaneous all-optical add and drop multiplexing of 40-Gbit/s OTDM signals using monolithically integrated Mach-Zehnder interferometer

K.S. Jepsen, B. Mikkelsen, M. Vaa, H.N. Poulsen,

A.T. Clausen, K.E. Stubkjaer, R. Hess,* M. Duelk,* W. Vogt,*

E. Gamper,* E. Gini,* P.A. Besse,* H. Melchior,*

S. Bouchoule,** Department of Electromagnetic Systems, Technical University of Denmark, Building 348, Technical. University of Denmark, DK-2800 Lyngby, Denmark; E-mail: kje@emi.dtu.dk

As a means to overcome electronic bottlenecks optical time-division multiplexing (OTDM) is well suited for long-distance, high-bit-rate transmission, ${ }^{1,2}$ e.g., for interconnecting large regional networks. A key component in an OTDM network is the all-optical add-drop multiplexer (AO-ADM), in which one or more channels are extracted and new channels inserted into the vacant timeslot(s). The AO-ADM must therefore provide a "complementary" demultiplexing for optically clearing a timeslot before adding a new channel. This is difficult to realize using methods such as, e.g., four-wave mixing, which has previously been used for demultiplexing. ${ }^{3}$ In this paper we demonstrate for the first time to our knowledge, that both regular demultiplexing and complementary demultiplexing with add-functionality can be performed simultaneously at $40 \mathrm{Gbit} / \mathrm{s}$ using a single semiconductor optical amplifier based, monolithically integrated MachZehnder interferometer (SOA-MZI).

The SOA-MZI structure is active-passive comprising passive waveguides with multimode interference couplers (MMI), and monolithically integrated SOAs in the two interferometer arms. The operation principle is ultrafast, based on differential injection of short control pulses into the interferometer arms and the device can operate at bit rates of $80 \mathrm{Gbit} / \mathrm{s}$ or more. ${ }^{4,5}$

The experimental setup is shown in Fig. 1. The short optical pulses needed for both the 40-Gbit/s signal, the 10-Gbit/s add signal and the control pulses are derived from gain-switched distributed feedback (DFB) lasers with dispersion-compensating fiber (DCF) pulse compression. The signal pulses are psuedo-random binary sequence (PRBS) modulated at $10 \mathrm{Gbit} / \mathrm{s}$. The signal for the "add" operation is tapped before passively multiplexing the "main" signal to a single polarization

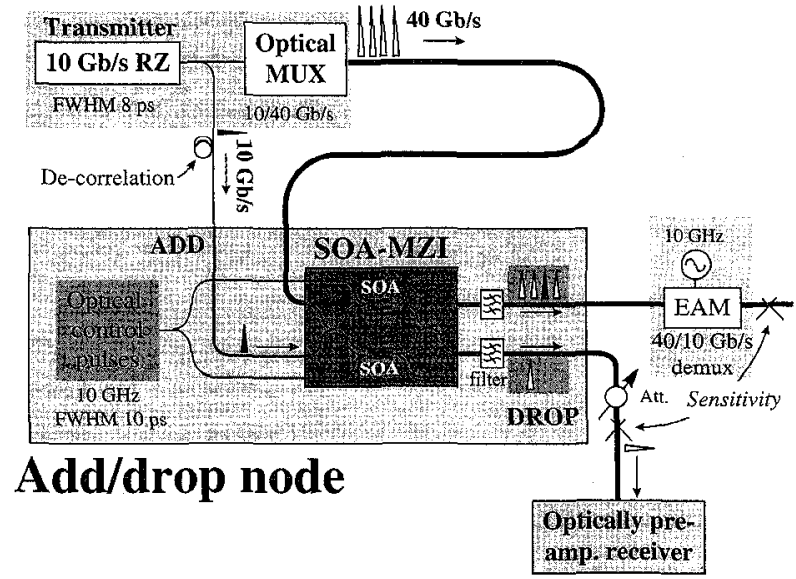

ThN2 Fig. 1. Schematic setup. 
40-Gbit/s bit stream. In the present experiments the add operation is performed after the device through a $3-\mathrm{dB}$ coupler (add through the second input arm of the device possible).

The simultaneous add/drop operation is accomplished by coupling the 40-Gbit/s signal into the SOA-MZI structure, and injecting the optical control pulses (co- and counter-propagation possible). The 10-Gbit/s demultiplexed and the complementary $3 \times 10 \mathrm{Gbit} / \mathrm{s}$ signals are thereby switched to the two outputs. The 10-Gbit/s "add" channel is de-correlated from the $40-\mathrm{Gbit} / \mathrm{s}$ signal through $75 \mathrm{~m}$ of single-mode (SM) fiber and added into the cleared timeslot at the worst-case polarization.

For error counting the $40 \mathrm{Gbit} / \mathrm{s}$ ( $=3 \times 10+10 \mathrm{Gbit} / \mathrm{s}$ ) signal is demultiplexed to $10 \mathrm{Gbit} / \mathrm{s}$ using an electroabsorption modulator. The complementary demux/add operation results in a moderate penalty of $1.3 \mathrm{~dB}$ when the EAM demux penalty of $1.1 \mathrm{~dB}$ is subtracted from the total system penalty of $2.4 \mathrm{~dB}$ (Fig. 2). The eye diagrams show the high quality demux and complementary demux. Note, that the penalty for cascading ADMs and clearing/adding into the same timeslot is limited to the penalty for passing a single node. This is because each successive complementary demultiplexing further suppresses the first signals cleared from the timeslot; thus, only the last node passed gives rise to penalty from the add-function. The dynamic range for the simultaneous add/drop operation is estimated to be in excess of $7 \mathrm{~dB}$.

The operation conditions can be optimized for the add operation alone at the expense of the quality of the regular demux. In this mode of operation the add-timeslot can be cleared perfectly and the penalty for adding can be reduced to only $0.3 \mathrm{~dB}$ (Fig. 3 ).
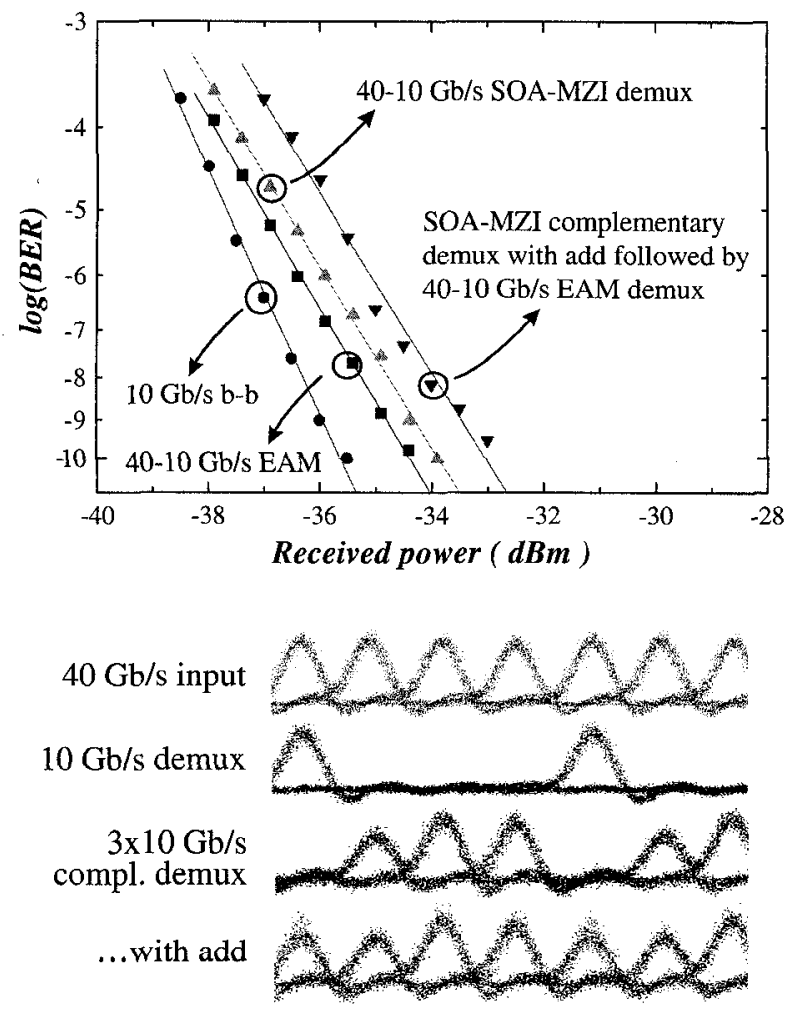

ThN2 Fig. 2. Measured BER vs. received power at $10 \mathrm{Gbit} / \mathrm{s}$ for simultaneous add and drop. Drop sensitivity $=-34.4 \mathrm{dBm}$; Total system penalty for clear/add (including EAM demux) $=2.4 \mathrm{~dB}=>$ Add penalty $=\sim 1.3 \mathrm{~dB}$. Eye diagrams show original $40 \mathrm{~Gb} / \mathrm{s}$ signal, simultaneous SOA-MZI demux and complementary demux without and with add.

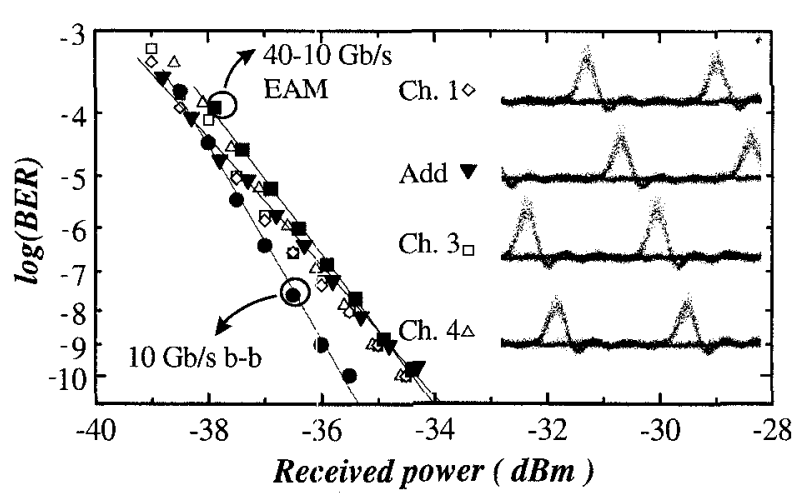

ThN2 Fig. 3. Measured BER vs. received power at $10 \mathrm{Gbit} / \mathrm{s}$ for all channels at optimised add operation. Add penalty $<0.3 \mathrm{~dB}$ relative, subtracting EAM demux penalty. Eye diagrams shown for all channels after EAM demux.

In conclusion, simultaneous all-optical add and drop multiplexing of a 40-Gbit/s OTDM signal using a monolithically integrated SOA-MZI is demonstrated. While maintaining a penalty of $1.3 \mathrm{~dB}$ for the add operation the sensitivity for the demultiplexed signal is $-34.4 \mathrm{dBm}$.

${ }^{*}$ Micro-and Optoelectronics, Institute of Quantum Electronics, ETH Hönggerberg, $\mathrm{CH}-8093$ Zürich, Switzerland

${ }^{*}$ France Telecom, CNET Laboratoires de Bagneux, Bagneux Cedex, France

1. A.D. Ellis et al., IEEE J. Lightwave Technol. 13, 761 (1995).

2. R.A. Barry et al., IEEE J. Select. Areas Commun. 14, 999 (1996).

3. O. Kamatani, S. Kawanishi, Electron. Lett. 32, 911 (1996).

4. M. Vaa et al., in Proceedings of European Conference on Optical Communication (ECOC'97), 1996, paper We1B3.

5. R. Hess et al., in Optical Amplifiers and their Applications, Vol. XVI of 1997 OSA Trends in Optics and Photonics Series (Optical Society of America, Washingtor, D.C., 1997), paper WA3.

2:15pm

\section{$20 \times 5$ Gbit/s optical WDM-TDM transmitter using a single-stripe multiwavelength mode-locked semiconductor laser}

H. Shi, P.J. Delfyett, G.A. Alphonse,* J.C. Connolly,* Center for Research and Education in Optics and Lasers (CREOL), University of Central Florida, Orlando, Florida 32816; E-mail: delfyett@faculty.creol.ucf.edu

Multiwavelength optical signal sources capable of generating ultrashort and highly synchronized picosecond pulses are of great interest in novel photonic networks utilizing combined optical wavelengthdivision multiplexed (WDM) and time-division multiplexed (TDM) data formats. To date, multiwavelength generation has been demonstrated by either using spectral filtering of femtosecond optical pulses, or semiconductor laser-based devices. ${ }^{1-5}$ In these approaches, the former is usually associated with great efforts to generate femtosecond optical pulses and low channel pulse rate, while the latter suffers from limited wavelength channels, and strong gain competition between the oscillating wavelengths, which is typically characteristic of semiconductor diode lasers.

In this paper, we demonstrate a tunable multiwavelength mode-locked semiconductor laser based on a single-stripe semiconductor optical amplifier (SOA). By actively mode-locking the single-grating-loaded external cavity semiconductor laser system, 20 wavelength channels are simultaneously 